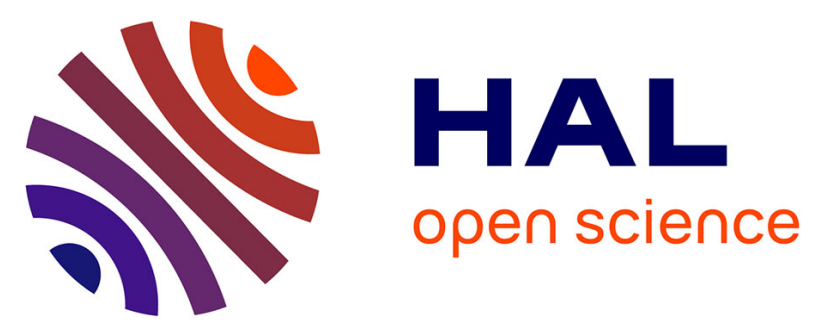

\title{
Repetitive movements and behaviors in neurological and psychiatric practice: Distinctions and similarities between Tourette disorder and obsessive-compulsive disorder
}

Andreas Hartmann, Bruno Millet

\section{To cite this version:}

Andreas Hartmann, Bruno Millet. Repetitive movements and behaviors in neurological and psychiatric practice: Distinctions and similarities between Tourette disorder and obsessive-compulsive disorder. Revue Neurologique, 2018, 174 (4), pp.199-202. 10.1016/j.neurol.2018.01.364 hal-01826549

\section{HAL Id: hal-01826549 \\ https://hal.sorbonne-universite.fr/hal-01826549}

Submitted on 29 Jun 2018

HAL is a multi-disciplinary open access archive for the deposit and dissemination of scientific research documents, whether they are published or not. The documents may come from teaching and research institutions in France or abroad, or from public or private research centers.
L'archive ouverte pluridisciplinaire HAL, est destinée au dépôt et à la diffusion de documents scientifiques de niveau recherche, publiés ou non, émanant des établissements d'enseignement et de recherche français ou étrangers, des laboratoires publics ou privés. 
Repetitive movements and behaviors in neurologic and psychiatric practice : Distinctions and similarities between Tourette Disorder and ObsessiveCompulsive Disorder

Andreas Hartmann ${ }^{1,2,3}$ et Bruno Millet ${ }^{3,4}$

1 - Centre National Maladie 'Syndrome Rare Gilles de la Tourette', Groupe Hospitalier PitiéSalpêtrière, Paris, France.

2 - Assistance Publique-Hôpitaux de Paris, Départment de Neurologie, Groupe Hospitalier Pitié-Salpêtrière, Paris, France.

3 - Sorbonne Universités, UPMC Université Paris 06, UMR S 1127, CNRS UMR 7225, ICM, Paris, France

4 Assistance Publique-Hôpitaux de Paris, Départment de Psychiatrie Adulte, Groupe Hospitalier Pitié-Salpêtrière, Paris, France.

Adress for correspondance :

Andreas Hartmann, MD

Département de Neurologie

Groupe Hospitalier Pitié-Salpêtrière

Paris / France

Tel. +33142161316

Email : andreas.hartmann@aphp.fr 
Repetitive movements and behaviors in neurologic and psychiatric practice : Distinctions and similarities between Tourette Disorder and ObsessiveCompulsive Disorder 
Abstract

Repetitive movements are a hallmark of chronic tic disorders such as Tourette disorder (TD) while repetitive behaviors characterize Obsessive Compulsive Disorder (OCD). Both disorders tend to frequently co-occur as a substantial number of patients with TD also suffer from OCD and vice versa. The clinical distinction between tics and OCD is usually easy but borderline forms exist. Also, correct symptom recognition is vital to chose the appropriate treatment modalities in both disorders, either pharmacologic, psychotherapeutic (behavioral therapy) or using brain stimulation (deep brain stimulation or repetitive transcranial magnetic stimulation).

Keywords : Tics ; Tourette disorder ; obsessive-compulsive disorder ; repetitive behaviors ; differential diagnosis

Abbrevations : OCD = obsessive-compulsive disorder ; SSRI = selective serotonin reuptake inhibitor ; TD = Tourette disorder

Conflicts of interest: None. 


\section{Introduction}

Both neurologists and psychiatrists have to cope with abnormal movements and behaviors. However, while neurologists primarily treat movement disorders, psychiatrists deal more frequently with behavioral disorders. Movement is defined by the act of moving, whereas behavior defines the way how one acts, especially toward others. This is the main distinction between tics, where symptoms are characterized by a movement dysfunction generally resulting from an urge-to-move or urge-to-do, and Obsessive Compulsive Disorder (OCD) in which a repetitive behavior responds to an obsessive and irrepressible set of thoughts. However, in certain forms of chronic tic disorders such as Tourette disorder (TD), repetitive complex movement can mimic OCD, while early-onset OCD is frequently associated with complex tics.

From a semiologic viewpoint, repetitive behaviors can occur in a large number of neurologic and psychiatric conditions. Generally, these movements will be labelled as abnormal (dystonia, parkinsonian tremor, catatonia etc), specifically movements or postures that appear non-physiological just by observing the patient. However, one can also witness movements that, when taken as such, are physiological but occur with an abnormal frequency and/or in an abnormal context: tics, stereotypies, mannerisms, compulsions. Regarding compulsions, we speak of behaviors rather than specific movements. Here, contextual anxiety is paramount, and in the majority of these cases clinical evaluation allows to identify obsessive phenomena underpinning the behavior.

\section{Tics}

Tics are the cameleons in the world of movement disorders : they may correspond to any kind of movements (motor tics) or vocalisations (vocal tics) occurring naturally, i.e. in everyday life. Depending on their complexity, they are labeled as simple (involving a single muscle or 
muscle group) or complex (involving several muscle groups). As a rule, simply observing the patient will not suffice : he or she must be interrogated about the presence (or absence) of a premonitory sensation (urge to do, urge to move) which precedes the tic and which is relieved by ticking, since premonitory sensations are usually experienced as uncomfortable. Note, however, that premonitory sensations are rarely present before the age of 10 [1]. Another feature of tics is that they can be repressed but only for limited periods (ranging between seconds and hours) and that tic suppression requires an effort .

When multiple motor and vocal tics occur in a chronic manner, we are confronted with Tourette disorder (TD). TD is defined by the DSM-5 [2] as the association of at least two motor tics and one vocal tic over a period of at least 12 months with an onset before age 18 (Table 1). Tics usually start in childhood between the age of 5-7 years and are thus initially pediatric [3].

OCD

OCD can be characterized by abnormal behaviors rather than movements. Compulsions are defined as repetitive and excessive behaviors the person is obliged to perform in response to intrusive and incoercible ideas; performing the compulsion will temporarily alleviate or interrupt these ideas which are labelled obsessions. Regarding the first DSM and ICD classifications, OCD was initially embedded into the category of anxiety disorders. Anxiety was considered as an essential dimension which mainly allowed to explain the relationship between obsessive thoughts and compulsive behaviors (for instance, "I am obsessed by the dirtyness, this causes anxiety, so I should wash my body" or on the other hand " not washing my hands causes a huge anxiety which might eventually initiate obsessive thoughts”). Today, the DSM-5 classification considers OCD as a distinct disorder, as part of the category of Obsessive Compulsive and Related Disorders, containing Body Dysmorphic Disorder, 
Hoarding Disorder, Trichotillomania, Excoriation Disorder and Substance/MedicationInduced Obsessive-Compusive and Related Disorder.

The major types of OCD are now well identified. The DSM-5 [2] (Table 2) distinguishes: (i) obsessions related to cleanliness or fear of contamination which are associated with washing rituals ; (ii) obsessions linked to the fear to harm oneself or close ones associated with checking rituals ; (iii) obsessions of symmetry or order associated with counting rituals or repetition compulsions; (iv) obsessive ideas linked to taboos such as sexuality or religious blasphemy associated with checking behaviors or purification rituals. It is crucial to understand the distinction between normal rituals and compulsive behaviors within the frame of OCD. While rituals, in children as well as in adults, correspond to rules and habits that contribute to the structuration of the individual's daily life, compulsions in OCD are defined by excessive and repeated behaviors that the patients must accomplish in order to alleviate anxiety and /or the frequency of obsessive thoughts. In that sense, OCD should be distinguished from stereotypies which should be considered as repetitive behaviors without a goal directed behavior.

Subjects suffering from OCD describe an intense and overwhelming anxiety when forced to confront their obsessions. They describe a feeling of discomfort and malaise driving the realization of the corresponding compulsion. This behavioral ritual, when appropriately accomplished, can provide a temporary feeling not only of respite but of satisfaction.

Another manifestation of OCD is avoidance behavior by trying to circumvent the obsession trigger. For instance, patients with contamination obsessions will avoid public toilets whereas those fearing to provoke a catastrophe will not drive their cars anymore.

Considering the clinical specificities of both OCD and tics, behavior on one hand, movement on another, it sounds - in principle - easy to establish a differential diagnosis. However, because both disorders sometimes present with excessive rules or habits sequences 
which lead to adjustment difficulties in daily life, the overlap between both syndromes is not rare and differential diagnosis tricky.

\section{Borderline forms}

Despite the obvious differences between tics and OCD, their border can be permeable, even more so since both conditions are frequently associated. For instance, some OC symptoms such as repetitive rituals of touching, obsessions of symmetry may look like complex tics. Additionally, in patients with TD, it is estimated that $60 \%$ also suffer from OCD [4]. Conversely, around $30 \%$ of patients suffering from OCD also display tics [5]. This temporal and symptomatic overlap might argue for a continuity between both syndromes.

In a large French study on adult patients suffering from TD, two thirds had repetitive behaviors [6]. These behaviors were analyzed both by a psychiatrist and a neurologist with an equal proportion of tics and OCD, but one fourth of patients also displayed mixed forms which could correspond either to tics or to OCD. From a phenomenological viewpoint, behaviors linked to washing/cleaning and checking could be attributed unequivocally to OCD. In borderline forms, symmetry and counting behavior as well as touching and just right behaviors were predominant.

Of note, the age of onset for tics and OCD is different. Tics usually start in childhood whereas OCD begins to manifest in late adolescence or early adulthood. Even though OCD can be considered a neurodevelopmental disorder, it is striking to see that tics are predominantly observed with early-onset OCD, while late-onset OCD is much less frequently associated with tics [7]. This might be in line with the different stages of the neurodevelopmental processes of habit procedures (learning skills) which, when becoming dysfunctional, could concern different deep brain structures [8]. 
Appropriate differential diagnosis is paramount in choosing the appropriate therapeutic course. With regard to pharmacologic interventions, tics usually respond to antipsychotics (typical and atypical), whereas OCD is targeted by using selective serotonin reuptake inhibitors (SSRI) as first choice treatments, and is treated with antipsychotics only in cases of lack of insight or delusional beliefs.

When using psychotherapeutic approaches, both tics and OCD can be treated by behavioral therapies with a common principle, exposure with response prevention $[9,10]$. In both disorders, this technique is destined to help the patient escape from pathological habits in which he or she is incarcerated. Nonetheless, it is essential to clearly identify the major symptom(s) in order to obtain an optimal result.

\section{Pathophysiology}

Anatomically, both tics and OCD have been linked to two cerebral structures interacting with each other : the cortex and the basal ganglia. The main hypothesis postulates dysfunctional loops of the cortico-striato-thalamo-cortical circuitry. The basal ganglia comprise the striatum (caudate nucleus and putamen), the pallidum (external and internal segment), the substantia nigra pars reticulata and the subthalamic nucleus. These nuclei receive afferences from the cortex and are subdivided into distinct loops : (i) sensori-motor (originating from the sensorimotor cortex), (ii) associative (originating from the dorsolateral prefrontal cortex and supplementary and pre- supplementary motor areas) and (iii) limbic (originating from the the orbitofrontal and anterior cingulate cortex) [11]. Each of these loops either commands movements (sensorimotor loop) or behaviors (associative and limbic loops) which can be altered variably both in TD and OCD depending on the symptoms and their severity.

Although both TD and OCD initially appear as goal-directed movements (to alleviate premonitory sensations) and behaviors (to alleviate obsessions and anxiety), they eventually 
transition into habits with time. For instance, in TD, habit formation has been shown to be enhanced in unmedicated patients due to aberrant reinforcement signals to the sensorimotor striatum which underly the formation of stimulus-response associations [12]. In OCD patients, excessive habits have been associated with hyperactivation of the caudate nucleus, previoulsy implicated in goal-directed behavior, which suggests that habit formation in OCD may result from impairments in this system, rather than differences in the buildup of stimulus-response habits as such [13]. Certainly, the coming years will allow to fine tune our understanding of the balance between goal-directed behaviors and habit formations in TD and OCD as well as other disorders (i.e. addictions), and the anatomical substrates involved [14].

Understanding neuronal circuitry also informs about available neuromodulation brain stimulation treatments, i.e. deep brain stimulation for severe pharmaco-resistant TD, and deep brain stimulation and repetitive transcranial magnetic stimulation in OCD. Whereas in TD motor circuits such as the globus pallidus (internal segment) or the thalamus (centromedian/parafascicular nucleus) are preferentially targeted [15], limbic targets are favoured in OCD such as the ventral striatum and the medial part of the subthalamic nucleus [16] as well as the orbitofrontal cortex OFC when using repetitive transcranial magnetic stimulation [17].

\section{Take home messages}

Similarities between tics and OCD are repetitive movements and behaviors which make a precise clinical differential diagnosis necessary. A special situation arises in France where the terms « tics » et « tocs » are often used interchangeably. Also, many patients suffering from chronic tics / TD also suffer from OCD and vice versa. In most cases, however, the clinical distinction will be relatively easy when exploring the physical, mental and emotional landscape of the patients when it comes to symptom manifestation (premonitory sensations / 
anxiety / mental imagery). The age of onset is also an important differentiator between TD and OCD. Finally treatment response, in case of doubt, might also be helpful (antipsychotics vS. SSRI). 


\section{References}

[1] Banaschewski T, Woerner W, Rothenberger A. Premonitory sensory phenomena and suppressibility of tics in Tourette syndrome: developmental aspects in children and adolescents. Dev Med Child Neurol 2003;45:700-3.

[2] APA. Diagnostic and Statistical Manual of Mental Disorders (DSM-5). Washington: American Psychiatric Association; 2013

[3] Leckman JF, Zhang H, Vitale A, Lahnin F, Lynch K, Bondi C, et al. Course of tic severity in Tourette syndrome: the first two decades. Pediatrics 1998;102:14-9.

[4] Hirschtritt ME, Lee PC, Pauls DL, Dion Y, Grados MA, Illmann C, et al. Lifetime prevalence, age of risk, and genetic relationships of comorbid psychiatric disorders in Tourette syndrome. JAMA Psychiatry 2015;72:325-33.

[5] de Vries FE, Cath DC, Hoogendoorn AW, van Oppen P, Glas G, Veltman DJ, et al. TicRelated Versus Tic-Free Obsessive-Compulsive Disorder: Clinical Picture and 2-Year Natural Course. J Clin Psychiatry 2016;77:e1240-e1247.

[6] Worbe Y, Mallet L, Golmard JL, Béhar C, Durif F, Jalenques I, et al. Repetitive behaviours in patients with Gilles de la Tourette syndrome: tics, compulsions, or both? PLoS One 2010 Sep 24;5:e12959.

[7] Millet B, Kochman F, Gallarda T, Krebs MO, Demonfaucon F, Barrot I, et al. Phenomenological and comorbid features associated in obsessive-compulsive disorder: influence of age of onset. J Affect Disord 2004;79:241-6.

[8] Rosenberg DR, Keshavan MS. A.E. Bennett Research Award. Toward a neurodevelopmental model of of obsessive--compulsive disorder. Biol Psychiatry1998;43:623-40.

[9] van de Griendt JM, Verdellen CW, van Dijk MK, Verbraak MJ. Behavioural treatment of tics: habit reversal and exposure with response prevention. Neurosci Biobehav Rev 2013;37:1172-7.

[10] Lewin AB, Wu MS, McGuire JF, Storch EA. Cognitive behavior therapy for obsessivecompulsive and related disorders. Psychiatr Clin North Am 2014;37:415-45.

[11] Krack P, Hariz MI, Baunez C, Guridi J, Obeso JA. Deep brain stimulation: from neurology to psychiatry? Trends Neurosci 2010;33:474-84.

[12] Delorme C, Salvador A, Valabrègue R, Roze E, Palminteri S, Vidailhet M, de Wit S, Robbins T, Hartmann A, Worbe Y. Enhanced habit formation in Gilles de la Tourette syndrome. Brain 2016 ;139:605-15.

[13] Gillan CM, Apergis-Schoute AM, Morein-Zamir S, Urcelay GP, Sule A, Fineberg NA, Sahakian BJ, Robbins TW. Functional neuroimaging of avoidance habits in obsessivecompulsive disorder. Am J Psychiatry 2015;172:284-93. 
[14] Gillan CM, Robbins TW, Sahakian BJ, van den Heuvel OA, van Wingen G. The role of habit in compulsivity. Eur Neuropsychopharmacol 2016;26:828-40.

[15] Baldermann JC, Schüller T, Huys D, Becker I, Timmermann L, Jessen F, et al. Deep Brain Stimulation for Tourette-Syndrome: A Systematic Review and Meta-Analysis. Brain Stimul 2016;9:296-304.

[16] Alonso P, Cuadras D, Gabriëls L, Denys D, Goodman W, Greenberg BD, et al. Deep Brain Stimulation forObsessive-Compulsive Disorder: A Meta-Analysis of Treatment Outcome and Predictors of Response. PLoS One 2015 Jul 24;10:e0133591.

[17] Nauczyciel C, Le Jeune F, Naudet F, Douabin S, Esquevin A, Vérin M, Dondaine T, Robert G, Drapier D, Millet B. Repetitive transcranial magnetic stimulation over the orbitofrontal cortex for obsessive-compulsive disorder: a double-blind , crossover study. Transl Psychiatry 2014;4:e436. 